\title{
Current Evidence-based Management of Patients on Antiplatelets and Anticoagulants in Dental Practice: A Questionnaire-based Survey of Interns and Staff
}

\author{
'Shazneen Firdosh Daruwalla, ${ }^{2}$ Sunil Sidana
}

\begin{abstract}
An increasing number of dental patients are taking 'blood thinner' medications for various medical conditions. These drugs interfere with the body's normal clotting (stopping blood flow) mechanism. The standard of care has been to stop the aspirin and warfarin prior to dental procedures involving bleeding since these drugs are known to affect clot formation and coagulation. However, the patient is at a greater risk of developing thromboembolic complications and reinfarcts if these drugs were discontinue than occurence of excessive bleeding if they were continued. Bleeding can be effectively managed by local hemostatic measures.
\end{abstract}

Keywords: Antiplatelets, Anticoagulants, Thromboembolism, Bleeding time, Prothrombin time.

How to cite this article: Daruwalla SF, Sidana S. Current Evidence-based Management of Patients on Antiplatelets and Anticoagulants in Dental Practice: A Questionnaire-based Survey of Interns and Staff. J Contemp Dent 2014;4(1):22-26.

Source of support: Nil

Conflict of interest: None

\section{INTRODUCTION}

An increasing number of dental patients are taking 'blood thinner' medications for various medical conditions. These drugs interfere with the body's normal clotting mechanism. The standard of care followed by physicians and dentists till now has been to stop the aspirin and warfarin prior to dental procedures involving bleeding since these drugs are known to affect clot formation and coagulation. However, the patient is at a greater risk of developing thromboembolic complications and reinfarcts if these drugs were discontinue than occurance of excessive bleeding if they were continued,

The study was carried out to determine, if recent evidence-based management of patients on aspirin and warfarin in relation to dental practice is followed by the dentists and future dentists (interns) of MGM Dental College and Hospital.

\footnotetext{
${ }^{1}$ Intern, ${ }^{2}$ Associate Professor

1,2Department of Oral and Maxillofacial Surgery, MGM Dental College and Hospital, Navi Mumbai, Maharashtra, India

Corresponding Author: Shazneen Firdosh Daruwalla, Intern Department of Oral and Maxillofacial Surgery, MGM Dental College and Hospital, Navi Mumbai, Maharashtra, India Phone: 022-27426604, e-mail: shazneen.d@gmail.com
}

\section{MATERIALS AND METHODS}

- A questionnaire study was carried out among 150 persons including the staff, postgraduates and interns of Mahatma Gandhi Mission Dental College. One hundred and fifty people of which 82 were interns, 32 were postgraduate students and 36 were among staff members who were included in the survey. Total of 10 questions were asked. They were asked to select the appropriate option for each question. Questions ranged from awareness of antiplatelet and anticoagulant drugs to their management in dental practice.

The questionnaire was as follows:

SURVEY ON MANAGEMENT OF PATIENTS ON ANTIPLATELETS AND ANTICOAGULANTS IN ORAL SURGERY

INTERN/ PG/ STAFF

Tick $(\mathrm{P})$ the appropriate option in the box provided

1. Aspirin is
(a) Antiplatelet
(b) Anticoagulant

2. How will you manage a patient on aspirin in oral surgery?

(a) Refer the patient to the physician

(b) Stop the drug

(c) Continue the drug

3. If the physician/dentist decide to stop aspirin therapy how long before the procedure should it be discontinued?
(a) 1 day
(b) 3 days
(c) 5 days
(d) 7 days
(e) 9 days

4. Clopidogrel is
(a) Antiplatelet
(b) Anticoagulant

5. What is risk of stopping aspirin?
(a) Thromboembolism
(b) Malaria
(c) Pneumonia
(d) Excessive bleeding 
6. Warfarin is
(a) Antiplatelet
(b) Anticoagulant

7. How will you manage a patient on warfarin before extraction?
(a) Refer the patient to the physician
(b) Stop the drug
(c) Continue the drug
(d) Carry out a blood test

8. What test will you advice before an oral surgery procedure if the patient is on warfarin therapy?
(a) BT
(b) INR
(c) $\mathrm{CBC}$

9. Which mouthwash should you prescribe in a patient on warfarin therapy?
(a) Chlorhexidine
(b) Betadine
(c) Tranexamic acid

10. How will you control bleeding in a patient on antiplatelets or anticoagulants?
(a) Local hemostatic measures
(b) Blood transfusion
(c) Not carry out the extraction in the first place

\section{RESULTS}

- Only $12 \%$ interns, $4 \%$ PGs and $22 \%$ staff decided to continue aspirin (Graph 1).

- Thirteen to twenty percent of them decided to stop warfarin before oral procedure. Forty to fifty percent decided to refer such patients to the physician.

- Thirty-two to fifty percent decided to carry out a blood test for patients on warfarin.

- Twenty to thirty percent did not correctly classify the drugs aspirin and warfarin as antiplatelets and anticoagulants respectively.

\section{DISCUSSION}

\section{Anticoagulant Therapy}

\section{Warfarin}

Patients can require warfarin therapy for various diagnoses, such as atrial fibrillation, pulmonary embolism, myocardial infarction, stroke, deep venous thrombosis (DVT) and antiphospholipid syndrome, or because they have prosthetic heart valves. ${ }^{1-5}$

The anticoagulant effect of warfarin takes 48 to 72 hours to develop fully, with an estimated duration of action of 2 to 5 days and a reported half-life of 2.5 days. However, several medications commonly prescribed by maxillofacial surgeons can affect the level of anticoagulation in patients taking warfarin. The medications that can potentiate effects of warfarin are broad-spectrum antibiotics, like metronidazole, salicylates, erythromycin. those which antagonize its effects are steroids, barbiturates, rifampin. Thromboembolic events are known to occur when warfarin is discontinued in the perioperative period. , $^{2,9,12-16}$

The prothrombin time or International normalized ratio (INR) must be checked regularly to ensure therapeutic anticoagulation status. ${ }^{6-11}$

Thirty percent interns, 50 to $60 \%$ were aware that INR is checked for a patient on warfarfin before any dental surgical procedure (Graph 2).

\section{ANTIPLATELET THERAPY}

\section{Aspirin}

Aspirin, acetylsalicylic acid, is a nonsteroidal anti-inflammatory drug that exhibits analgesic, antipyretic, anti-infla-

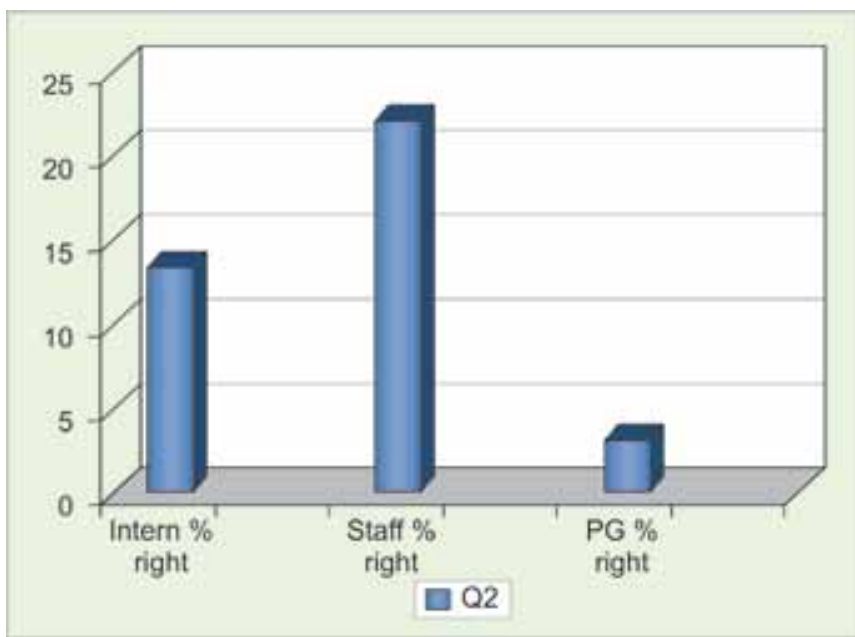

Graph 1: In management of patients on aspirin in dental surgical procedures (\% of interns, staff and postgraduates who decided to continue aspirin therapy)

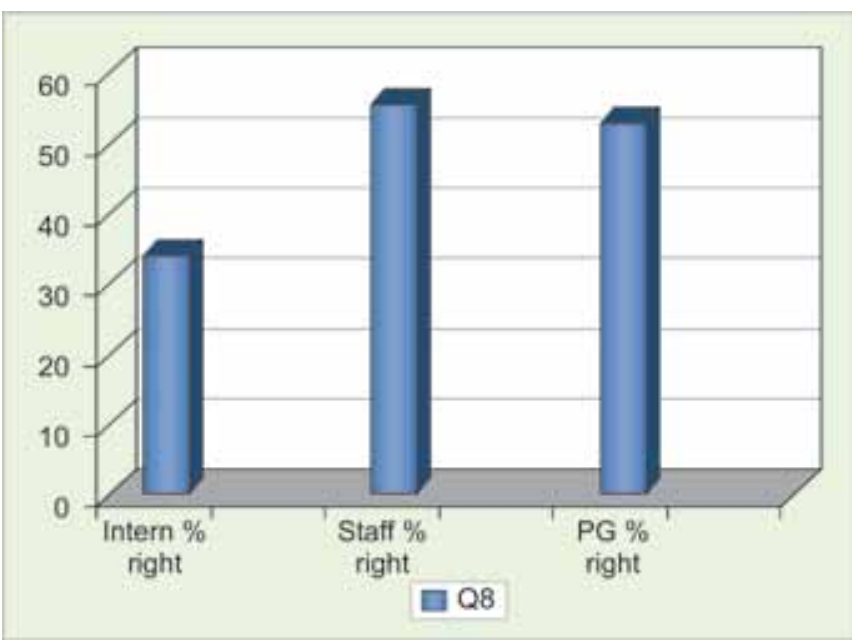

Graph 2: Test adviced before an oral surgical procedure in patients on warfarin therapy (INR-International Normalized Ratio) 
mmatory and antiplatelet properties. Aspirin has been shown to be a powerful secondary prevention agent, reducing the risk of myocardial infarction and ischemic stroke by up to $20 \%$ in patients diagnosed with cardiovascular disease. ${ }^{17}$ Its mechanism of action involves an irreversible inhibition of the activity of cyclooxygenase- 1 and a modification of the enzymatic activity of cyclooxygenase-2. Cyclooxygenase is an enzyme responsible for the conversion of arachidonic acid to prostaglandins, prostacyclin and thromboxane. Thromboxane-A2 is a specific eicosanoid lipid found in platelets important in promoting platelet aggregation over damaged endothelium in blood vessels.

The irreversible nature of the inhibition of cyclooxygenase is unique to aspirin among its counterparts. ${ }^{2,17}$ Platelets are affected for the life of the cell, and complete reversal of antiplatelet activity might not occur until approximately 2 weeks after cessation of therapy. The best screening test to evaluate the effect of aspirin on platelets is the platelet function analyzer-100, which is equally effective and less invasive than the Ivy bleeding time. In the past, it has been commonly recommended that the administration of antiplatelet drugs should be discontinued 7 to 9 days before surgery, so that sufficient numbers of normal circulating platelets can be regenerated. Currently, the discontinuation of aspirin therapy is rarely recommended. ${ }^{2-16,18}$

Only $12 \%$ interns, $4 \%$ PGs and $22 \%$ staffdecided to continue aspirin according to the survey (see Graph 1).

\section{CLOPIDOGREL}

Clopidogrel is an antiplatelet drug with a mechanism of action causing irreversible inhibition of an adenosine diphosphate receptor important in promoting platelet aggregation and cross-linking of platelets by fibrin. It is first activated in the liver by cytochrome $\mathrm{P} 450$ enzymes and has an estimated half-life of 8 hours. ${ }^{9}$ Clopidogrel has been identified as an independent risk factor for re-exploration after coronary artery bypass grafting. ${ }^{19}$

Many patients might be receiving a combination of antiplatelet drugs (e.g. aspirin and clopidogrel). This combination has been shown to cause bleeding complications much greater for combined therapy than for single-drug therapy. No large trials have been performed to evaluate the risk of bleeding complications with combined antiplatelet therapy. A recent survey of vascular surgeons showed that most did not stop the administration of antiplatelet drugs preoperatively. ${ }^{20}$

\section{EVIDENCE-BASED DENTISTRY}

\section{Patients on Aspirin}

Ardekian et al conducted a randomized controlled trial to evaluate the effect of aspirin on bleeding in patient undergoing oral surgery. Thirty-nine patients were randomly divided into two groups: those who stopped aspirin therapy before procedure and those who continued the aspirin therapy. All patients were receiving $100 \mathrm{mg}$ of aspirin daily on a regular basis. Also 1 hour before the procedure, all patients underwent a bleeding time test. Results showed that in both groups the bleeding time were within the normal range and in both groups a local hemostatic method was sufficient to control bleeding. No episode of uncontrolled intraoperative or postoperative bleeding were noted. They concluded that low dose aspirin should not be stopped before oral surgery and risk thromboembolic, cerebrovascular or myocardial complications. ${ }^{21}$

Fifty to sixty percent interns, staff and postgraduate students correctly identified thromboembolism as the risk of stopping aspirin (Graph 3).

Minor surgical procedures can be safely carried out without altering the antiplatelet medication dose. Those likely to be carried out in primary care (using local hemostatic measures) will be classified as minor, e.g. simple extraction of up to three teeth, gingival surgery, crown and bridge procedures, dental scaling and the surgical removal of teeth. $^{22}$

\section{Patients on Warfarin}

Evans et al conducted a randomized controlled trial to investigate whether patients who were taking warfarin and had an INR within the normal therapeutic range require cessation of their anticoagulation drugs before dental extractions. Of 109 patients who completed the trial, 52 were allocated to the control group (warfarin stopped 2 days before extraction) and 57 patients were allocated to the intervention group (warfarin continued). The incidence of bleeding complications in the intervention group was higher $(15 / 57,26 \%)$ than in the control group $(7 / 52,14 \%)$ but this difference was not significant. Two patients in the study required hospital review for bleeding and all other episodes of bleeding were controlled by patients at home. Continuing warfarin when the INR is 4.1 may lead to an increase in minor postextraction bleeding after dental extractions but they found no evidence of an increase in clinically important bleeding.

They concluded that as there are risks associated with stopping warfarin, the practice of routinely discontinuing it before dental extractions should be reconsidered. ${ }^{23}$

Forty-five percent interns, $60 \%$ staff and $75 \%$ postgraduate students identified local hemostatic methods as methods to control bleeding in patients on antiplatelets and anticoagulants in dental surgerical procedures (Graph 4).

When more than three teeth need to be extracted multiple visits will be required. The extractions may be planned to 


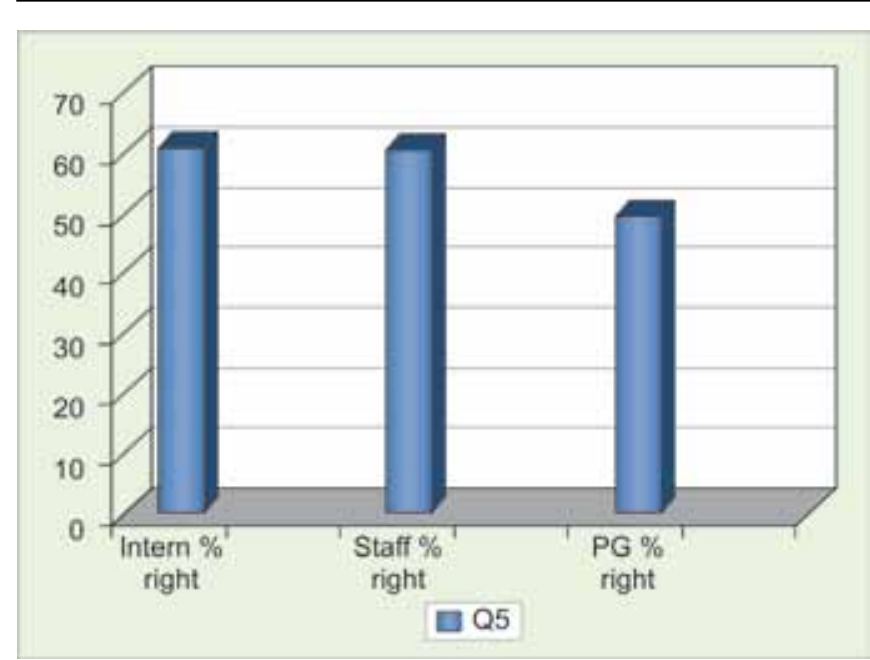

Graph 3: Risk of stopping aspirin (thromboembolism)

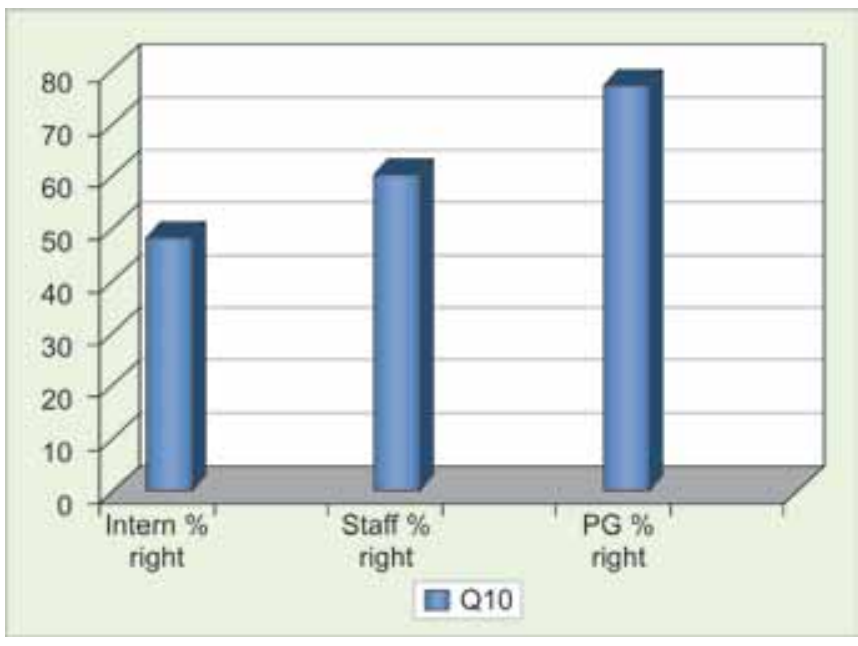

Graph 4: Methods to control bleeding in patients on antiplatelets and anticoagulants in dental surgical procedures (local hemostatic methods)

remove two to three teeth at a time, by quadrants or singly at separate visits.

Scaling and gingival surgery should initially be restricted to a limited area to assess if bleeding is problematic.

\section{LOCAL HEMOSTATIC MEASURES}

Many different materials have been used as local hemostatic agents by oral and maxillofacial and trauma surgeons. Surgeons most often use a hemostatic matrix, such as oxidized regenerated cellulose, absorbable gelatin, or collagen with suture applied to the extraction socket. The hemostatic properties of these agents are based on their ability to activate the coagulation cascade locally. They have no intrinsic coagulation factors or activity but are designed to stimulate clot formation by providing a three-dimensional scaffold used for clot organization. ${ }^{24-26}$

\section{SUMMARY}

- Do not stop aspirin before dental procedure.

- Check INR if patient is on warfarin.



Graph 5: An overview of the result of the questionnaire

- If INR is $<4$ carry out extraction. If INR $>4$ refer to cardiologist.

- Apply local hemostatic measures and give proper postoperative instructions.

\section{CONCLUSION}

Based on this survey, there is lack of awareness among dental professionals practicing dentistry and specialized dentistry and future dentist (interns) about current evidencebased management of patients on antiplatelets and anticoagulants (Graph 5).

\section{ACKNOWLEDGMENTS}

I would like to thank Dr Sunil Sidana, Reader, Department of Oral and Maxillofacial Surgery, MGM Dental College and Hospital, Kamothe, Navi Mumbai for his valuable support.

\section{REFERENCES}

1. Mehra P, Cottrell DA, Bestgen SC, et al. Management of heparin therapy in the high-risk, chronically anticoagulated, oral surgery patient: a review and a proposed nomogram. J Oral Maxillofac Surg 2000;58:198.

2. Sear JW, Higham H. Issues in the perioperative management of the elderly patient with cardiovascular disease. Drugs Aging 2002;19:429.

3. Cunningham LL Jr, Brandt MT, Aldridge E. Perioperative treatment of the patient taking anticoagulation medication. Oral Maxillofac Surg Clin North Am 2006;18:151.

4. Ananthasubramaniam K, Beattie JN, Rosman HS, et al. How safely and for how long can warfarin therapy be withheld in prosthetic heart valve patients hospitalized with a major hemorrhage? Chest 2001;119:478.

5. Solomon JM, Schow SR. The potential risks, complications and prevention of deep vein thrombosis in oral and maxillofacial surgery patients. J Oral Maxillofac Surg 1995;53:1441.

6. Little H, Miller CS, Henry RG, et al. Antithrombotic agents: Implications in dentistry. Oral Surg Oral Med Oral Pathol Oral Radiol Endod 2002;93:544. 
7. Rodgers GM. Thrombosis and antithrombotic therapy, in Lee GR, Foerster J, Lukens J, et al, editors. Wintrobe's Clinical Hematology. 10th ed. Philadelphia, Lippincott Williams and Wilkins 1999;1781-1821.

8. Hylek EM, Heiman H, Skates SJ, et al. Acetaminophen and other risk factors for excessive warfarin anticoagulation. JAMA 1998;279:657.

9. Harder S, Klinkhardt U, Alvarez JM. Avoidance of bleeding during surgery in patients receiving anticoagulant and/or antiplatelet therapy: pharmacokinetic and pharmacodynamic considerations. Clin Pharmacokinet 2004;43:963.

10. Holbrook AM, Pereira JA, Labiris R, et al. Systematic overview of warfarin and its drug and food interactions. Arch Intern Med 2005;165:1095.

11. Ansell J, Hirsh J, Poller L, et al. The pharmacology and management of the vitamin $\mathrm{K}$ antagonists: the seventh ACCP conference on antithrombotic and thrombolytic therapy. Chest 2004; 126:204S.

12. Campbell JH, Alvarado F, Murray RA. Anticoagulation and minor oral surgery: should the anticoagulation regimen be altered? J Oral Maxillofac Surg 2000;58:131.

13. Dunn AS, Turpie AG. Perioperative management of patients receiving oral anticoagulants: a systematic review. Arch Intern Med 2003;163:901.

14. Phan TG, Koh M, Wijdicks EF. Safety of discontinuation of anticoagulation in patients with intracranial hemorrhage at high thromboembolic risk. Arch Neurol 2000;57:1710.

15. Wahl MJ. Dental surgery in anticoagulated patients. Arch Intern Med 1998;158:1610

16. Yasaka M, Naritomi H, Minematsu K. Ischemic stroke associated with brief cessation of warfarin. Thromb Res 2006;118:290.
17. Lewis HD, Davis JW, Archibald DG, et al. Protective effects of aspirin against acute myocardial infarction and death in men with unstable angina: results of a veterans administration cooperative study. N Engl J Med 1983;309:396.

18. Merritt JC, Bhatt DL. The efficacy and safety of perioperative antiplatelet therapy. J Thromb Thrombolysis 2002;13:97-103.

19. Yende S, Wunderink RG. Effect of clopidogrel on bleeding after coronary artery bypass surgery. Crit Care Med 2001;29: 2271.

20. Asasantin summary of product characteristics, boehringer ingelheim limited. Available at: www.emc.medicines.org.uk accessed 22/11/06.

21. Tierney LMJ, McPhee SJ, Papadakis MA, editors. Current medical diagnosis and treatment. 40th ed. McGraw-Hill: New York 2002;p. 548.

22. Mitchell SM, Sethia KK. Hazards of aspirin withdrawal before transurethral prostatectomy. BJU Int 1999;84:530.

23. Evans, et al. Can warfarin be continued during dental extraction? Results of a randomized controlled trial. British Journal of Oral and Maxillofacial Surgery 2002;40:248-252.

24. Clopidogrel (Drug evauation) Klasco RK. editor. Drugdex ${ }^{\circledR}$ system (electronic version). Thomson micromedex, greenwood village, Colorado, USA. Available at: www.thomsonhc.com/ (accessed 01/05/07).

25. Ardekian L, Gaspar R, Peled M, Brener B, Laufer D. Does lowdose aspirin therapy complicate oral surgical procedures? J Am Dent Assoc 2000;131:331-335.

26. Alam M, Goldberg LH. Serious adverse vascular events associated with perioperative interruption of antiplatelet and anticoagulant therapy. Dermatol Surg 2002;28:992-998. 